\title{
Rol del sinésteta organizacional en el manejo de la comunicación asertiva
}

\section{Role of the organizational synaesthete in the management of assertive communication}

DOI: http://dx.doi.org/10.17981/econcuc.38.2.2017.05

Recibido: feb 5/2017 Devuelto para revisión: may 15/17 Aceptado: ago 25/2017

\author{
María Fernanda Hernández ${ }^{1}$ \\ Ramiro Aurelio Buitrago ${ }^{2}$
}

\begin{abstract}
Resumen
En las organizaciones existen caracteres y rasgos excepcionales en la interrelación de las personas que configuran una estructura de comunicación informal dentro de ellas, en este contexto, el presente artículo se orienta a comprender el rol de la personalidad sinestésica en las instituciones modernas, así como su aporte en la constitución de una cultura de comunicación asertiva. Se utilizó el método hermenéutico, con el que, a través de reducciones sistemáticas, se evidenció que la sinestesia abre un abanico de oportunidades que brinda a la organización dinamismo, multiplicidad y creatividad, así como la oportunidad de producir resultados beneficiosos en los procesos de comunicación.
\end{abstract}

Palabras clave: sinestesia; sinésteta organizacional; comunicación asertiva; sinestésicos egregios; sensopercepción.

\begin{abstract}
In organizations there are exceptional features and traits in the people's interrelation of the people which form an informal communication structure within them, in this context, this article is guided to understand the synesthetic personality role in modern institutions, as well as his contribution to the constitution of an assertive communication culture. The hermeneutic method was used, where through systematic reductions it was evidenced that the synesthesia opens a range of opportunities that gives to the organization dynamism, multiplicity and creativity, as well as the opportunity to produce beneficial results in communication processes.
\end{abstract}

Keywords: Synesthesia; organizational synesthesia; assertive communication; egesting synesthetics; sensing.

\footnotetext{
${ }^{1}$ Doctora en Ciencias Gerenciales. Magister Scientarium en Ciencias de la Comunicación. Docente investigador, Universidad Nacional Experimental de la Seguridad - UNES. Correo: maryfer_mm@hotmail.com

${ }^{2}$ Doctor en Ciencias Gerenciales. Magister Scientarium en Gerencia de Recursos Humanos. Abogado. Investigador independiente. Correo: abogbuitrago86@gmail.com
} 


\section{Introducción}

Desde los albores de la humanidad, el proceso comunicacional y todos sus referentes se encuentran incrustados de manera intrínseca en el hombre debido a su naturaleza de carácter social. El individuo en sí es un mar complejo donde se funden indistintos organismos que permiten la creación de una efigie personal. Elementos heredados como la constitución corporal, o algunos adquiridos posteriormente, como el temperamento o el carácter, constituyen la esencia básica del ser homínido.

Actualmente, las organizaciones han tomado un rumbo más humanizado y flexible, donde uno de sus principales objetivos es generar resultados orientados al bienestar social, personal y psicológico de los trabajadores. Para que una institución se encuentre dentro de los ámbitos calculados como productivos, es necesario que los elementos que conforman parte del personal se encuentren alineados a la misma causa. Ello incluye: identidad, valores y competencias, así como un conocimiento pleno de las metas a alcanzar. Si no existe una comprensión entre los participantes y una relación de comunicación asertiva entre ellos, cada unidad personal podría estar trabajando bajo su propio rumbo, sin sentido de bienestar colectivo alguno.

En este sentido, para establecer procesos efectivos de comunicación, es necesario comprender que cada personaje, a pesar de conformar parte de un todo, actúa como una entidad aparte y propia que mantiene sus propias creencias y rituales. La identificación personal está entrañablemente unida a las capacidades y labores que puede llevar a cabo el sujeto en sí, lo cual conduce al espectro de la personalidad conformada como elemento potenciador de las acciones externas.

De acuerdo con Bermúdez, Pérez-García, Ruíz, Sanjuán y Rueda (2013), la personali- dad es un constructo hipotético que consta de ciertos elementos (rasgos o disposiciones internas) perdurables en el tiempo, las cuales abarcan tanto la conducta expresamente manifiesta a la sociedad, como las experiencias privadas que puedan poseerse. Sin embargo, existen algunas variaciones que pueden presentarse, como por ejemplo influencias externas que causan alteraciones en períodos en los cuales el sujeto está más vulnerable (episodios de pérdida, adolescencia, entre otros), o características psicofísicas hereditarias que representen capacidades básicas del individuo.

Aunque la personalidad humana tiene pocos caracteres hereditarios, Dunn y Plomin (1984), en su estudio de la significancia del temperamento, señalan que el nivel de actividad sensorial se encuentra entre los tres rasgos heredados de la personalidad. Es precisamente este atributo, el que hace que algunas personas prefieran, por ejemplo, de acuerdo con su condición hereditaria, practicar deportes extremos, mientras otras seleccionarían un juego de mesa. La propensión al estrés, la forma prudente de tomar riesgos, el tradicionalismo, la tendencia a ser obediente o desobediente a la autoridad son rasgos de la personalidad que vienen determinados por este temperamento que viene condicionado desde el nacimiento.

Al respecto, Harrison (2004) describe a la sinestesia como una alteración sensoperceptiva, de carácter hereditario, en donde las personas experimentan, a través de la estimulación de un sentido, una reacción sensorial de distinta percepción; así, las personas sinestésicas son capaces de ver el color de la música, tocar las palabras o, incluso, sentir el olor de alguna figura geométrica. A pesar de la incomprensión que produce en la mayoría popular, Hathaway y McKinley (1967), a través del Inventario Multifásico de Personalidad de Minnesota (MMPI), han calificado a las personas poseedoras de esta facultad cognitiva como individuos dentro de los límites de la nor- 
malidad psicológica. Un sujeto sinestésico puede, por ejemplo, ver el número cinco de color rojo, coligar el día sábado con el color verde, o sentir calor agradable cuando escucha un determinado timbre de voz; así, las asociaciones de las personas que poseen esta cualidad son tan variadas que hace las posibilidades de reacción infinitas.

Esta característica tan peculiar es fomento de innumerables decisiones que toman estas personas basándose meramente en lo que el sexto sentido de la sinestesia les puedes indicar. Hay individuos sinestésicos que axiomáticamente tienen por principio no frecuentar lugares donde por ejemplo abunden los colores neón, pues es como si les escociera la piel, mientras que otros prefieren evitar los sonidos repetitivos (como el de una charrasca de metal) pues indican que es similar a sentir miles de uñas arrastrándose sobre la capa de su epidermis, esto solamente por citar algunos modelos en donde la sinestesia puede actuar de manera negativa.

A primera vista, parece un extraño don de la naturaleza, sin embargo, a medida que se va conociendo esta particularidad en el sentido de algunas personas, se hace evidente que no solamente existen personas sinestésicas, sino también organizaciones completas que poseen esta facultad. Es el caso de instituciones que asocian ciertas oportunidades con elementos o formas negativas y se estancan, o que por el contrario tienen la intuición suficiente como para percibir un buen negocio apenas escuchan de él, tal como si estuviesen "oliendo" las oportunidades que el rostro de una persona les trae.

Nace de esta manera un nuevo término que hace referencia a organizaciones únicas, tan diversas como las posibilidades sinestésicas que puede haber en la humanidad; empresas dinámicas con características especiales capaces de ver más allá de lo que sus sentidos principales les indican.
Son agrupaciones que, desde su fundación, fueron concebidas de esta manera, y que tal vez por los rasgos hereditarios de sus fundadores, han evolucionado constantemente dándole paso a un buen manejo de la comunicación asertiva, tanto entre sus empleados como en el trato hacia las demás organizaciones que conviven dentro de su entorno. La expresión de identidad de una empresa viene determinada por lo que ésta es, y la delimitación de la misma es manifestada por sus acciones (comunicativas).

Como resultado de estas competencias organizacionales, puede surgir una infinidad de teorías que permitan desarrollar capacidades que las empresas de hoy en día aún no sueñan con conocer. Es esta una investigación documental y analítica, determinada por las inquietudes y experiencias personales que, sumadas al apoyo teórico e investigativo realizado, han ido conformando el entramado que se despliega. En este artículo, se ofrece un vistazo claro y actualizado acerca la identidad corporativa, personalidad de las empresas y sinestesia organizacional, así como su influencia sobre la comunicación asertiva.

Sinestesia: Descubriendo el color de los números, el sabor de las imágenes y la temperatura de la música

La gestación de la sinestesia, así como sus orígenes dentro del cerebro humano, son entresijos que la neurociencia aún trata de resolver. Aunque usualmente se le asocia con un modo inusual de percepción, el grado de la misma puede variar, dependiendo de la persona que la experimente. Una persona normalmente escucha los sonidos, siente los sabores y ve las imágenes. Sin embargo, no siempre es así. Para Cytowic (1989), citado en Contreras, Botella, Cabestrero y Gil-Gómez (2013), la palabra sinestesia proviene del griego -syn (que quiere decir unión) y -aisthesis (que quiere decir sentido), consistiendo así en la mezcla o unión de varios sentidos, los cuales, al ser despertados por 
un estímulo determinado, pueden despertar reacciones multisensoriales que, en su mayoría, varían de persona a persona.

Desde esta perspectiva, la sinestesia se manifiesta de diversas maneras. En algunos casos, el sonido de un tema musical se puede acompañar de figuras diversas como círculos o triángulos, en otros, por ejemplo, se puede asociar algún tipo de dolor específico a un color. El caso más frecuente de sinestesia, de acuerdo con Day (2005, citado en Contreras y otros, 2013), es la asociación de un color a un determinado grafema, bien sea éste una palabra o un número. De esta manera, las personas que poseen este tipo de sinestesia pueden literalmente ver el color de los números, letras, palabras, días de la semana y hasta meses del año.

Un individuo sinestésico se puede diferenciar de los demás acromáticos gracias a la percepción de colores (dentro del espectro del arco iris) al ver o escuchar el sonido de una palabra, mientras que otro que experimente un tipo de sinestesia más vívida puede incluso llegar a ver colores únicos, a los que generalmente suelen referirse como indescriptibles. Incluso, se han documentado casos en los cuales, en vez de asociar un color específico, se observan patrones constructos de la propia mente (rayas anaranjadas con fondo negro, esferas rosadas orbitando sobre verde), por solamente brindar un ejemplo de lo que la mente sinestésica realiza.

En consecuencia, se presenta un espectro infinito de posibilidades, tantas como seres humanos hay con esta variación. Sin embargo, a pesar de la diversidad, existen rasgos distintivos que caracterizan esta particularidad de los sentidos. De acuerdo con De Córdoba y Riccò (2012), existen tres factores fundamentales que, luego de ser cuidadosamente estudiados, han permitido a los neurocientíficos calificar a un individuo como elemento manifiesto en este tipo de condición: la prevalencia, la consistencia y la objetivación.

De acuerdo con Sinner y otros (2006, citados en De Córdoba y Riccò, 2012), en un estudio realizado en una población de estudiantes universitarios, un número mayor al 4\% manifestaba al menos una forma de sinestesia, siendo la más común entre ellas la modalidad de grafema-color, la cual consiste en la asociación directa o indirecta de elementos (fonemas, signo lingüístico, números) a determinados colores. Según la disertación expuesta por los autores mencionados anteriormente y con base en los resultados obtenidos, la cualidad sinestésica prevalece, es decir, tiene superioridad o ventaja frente a los demás sentidos. Si bien no se habla de una distorsión sensorial (la persona sinestésica ve y oye tal cual como lo haría otra persona), se observa que la misma sobresale e incide en los límites de la personalidad manifiesta del ser humano que posee esta condición.

En este mismo sentido, para De Córdoba y Riccò (2012), la mayoría de los sujetos sinestésicos coinciden en la involuntariedad y permanencia en el tiempo de esta condición. Sin embargo, existen casos muy excepcionales en los cuales una situación específica, como, por ejemplo, un accidente de tránsito o algún fuerte trauma, ha logrado desarrollar en los individuos un tipo de sinestesia casual, la cual escapa a todo tipo de patrón estudiado previamente debido a que las causas generadoras no forman parte del genotipo de la persona en cuestión.

Asimismo, la sinestesia suele ser un estado consistente de la persona; partiendo de ello se comprende que quien de pequeño asociaba el día miércoles con el color anaranjado puede seguir viéndolo de esta manera a medida que transcurre el tiempo de su existencia, llevándole años o incluso décadas sin que este patrón se vea modificado de manera alguna. No obstante, puede haber casos muy originales, como el estudio cul- 
minado por Riggs y Karwoski (1934, citados en De Córdoba y Riccò, 2012), en el cual una niña sinestésica de siete años de edad manifestaba tener experiencias sensoriales asociadas a colores al momento de escuchar una nota musical o de conocer a una persona. Aunque el color de las distintas personalidades era persistente (su mamá tenía una personalidad verde y su papá azul), el de las notas musicales variaba según el instrumento que las interpretaba.

En ese mismo contexto, cabe destacar la objetivación de la sinestesia; aun tomando como un hecho verídico que la sinestesia venga heredada por el factor genético, existen variedades individuales. Cada persona ajusta a su propia razón los objetos de significado-significante, sin que ello responda en lo absoluto a ninguna ley o genoma previamente prescrito. Una familia, por ejemplo, en donde la madre y la hija presenten signos claros de sinestesia, puede ser divergente; mientras que para la madre el mes de agosto es rosado sin lugar a dudas, la hija puede mantener firmemente que el período de tiempo comprendido entre julio y septiembre es verde-amarillo.

Aunque las asociaciones suelen ser muy variadas, existen tipos de sinestesia que a lo largo del tiempo se han repetido constantemente. De acuerdo con De Córdoba y Gómez (2014), existen sinéstetas de múltiple concurrencia, en donde existe más de un elemento asociado al estímulo que se está recibiendo. De esta manera, un sinésteta múltiple puede percibir el número cinco no solamente como amarillo, sino también como cálido. No obstante, es muy poco frecuente; lo usual es que, al manifestar diferentes tipos de sinestesia, la persona evoque un solo concurrente diferente para cada inductor o estímulo que se esté percibiendo.

De igual manera, aunque la sinestesia grafema-color es la más habitual, es conveniente hacer referencia a la particularidad persona-color, la cual podría influir consi- derablemente en las actitudes de la persona que la posee. Dentro de esta modalidad, el sinésteta asocia, idiosincráticamente, el temperamento de un sujeto conocido o desconocido, a un color determinado. Para De Córdoba y Gómez (2014), este tipo de sinestesia se conoce como tipo aura, pues a una personalidad determinada se le asocia un color fantasma, el cual puede variar de tamaño, forma o ubicación, como es el caso que describe Cytowic (1989, citado en De Córdoba y Gómez, 2014) de un individuo que apenas distingue el rostro de las personas, pues él mismo se ve interrumpido por una niebla que varía según el tipo de personaje.

Aunque parezca que el estímulo no tiene ninguna relación con la sensación, cada sinésteta mantiene un significado particular y muy propio acerca de lo que se siente, y esta situación depende también del tipo de sinestesia áurica que se tenga. Para Iborra (2011, citado en De Córdoba y Gómez, 2014), existen siete variaciones de la sinestesia tipo aura, entre las cuales se encuentran las siguientes:

Tabla 1

Variaciones de la sinestesia tipo aura.

\begin{tabular}{|c|c|c|}
\hline Inductor & Concurrente & Modelo \\
\hline Persona & Color & "Raúl es verde" \\
\hline Emoción & Color & $\begin{array}{l}\text { "La alegría es } \\
\text { amarilla" }\end{array}$ \\
\hline Movimiento & Color & $\begin{array}{l}\text { "El ballet es } \\
\text { rojo" }\end{array}$ \\
\hline Persona & Animal & $\begin{array}{l}\text { "María es una } \\
\text { gata" }\end{array}$ \\
\hline Persona & Número & $\begin{array}{c}\text { "Tú eres un } \\
\text { diez" }\end{array}$ \\
\hline Persona & Nombre-objeto & $\begin{array}{l}\text { "Yo soy un } \\
\text { puente" }\end{array}$ \\
\hline Persona & Temperatura & $\begin{array}{l}\text { "Mi mamá es } \\
\text { cálida" }\end{array}$ \\
\hline
\end{tabular}

Fuente: elaboración propia con base en De Córdoba y Gómez (2014). 
Tal es el caso titulado Mi mejor amigo tiene un color desagradable, descrito por Milán y colaboradores (2007, citado por De Córdoba y Gómez, 2014), en donde un sujeto observa una especie de mancha colorida en su mente cada vez que conoce a una persona. A este respecto, categoriza esta especie de aura según su valencia emocional. Por ejemplo, los individuos que se caracterizan por ser muy emotivos y alegres, presentan un fotismo de color violeta; aquellos que le resultan amigables los asocia con el color rojo; mientras que a las personas desagradables o repulsivas las identifica con el color verde. En cuanto a su mejor amigo de la infancia, lo identifica con el color marrón, el cual está destinado para aquellos sujetos que poseen poca autoestima y manifiestan en general un estilo de vida pusilánime.

Las afirmaciones anteriores indican que, a través de la relación color-persona, este sinésteta realiza juicios de valor acerca de los individuos que generan estas sensaciones. Situación que puede incidir en diversos ámbitos de su vida, tanto personal como laboral. Aunque su mejor amigo le produzca visiones de este color desagradable, éste seguirá siendo su compañero, simplemente porque así lo escogió el sinésteta cuando lo identificó como una persona vulnerable. Ahora, la manera en que este tipo de condición influye en las respuestas emocionales es evidente, por lo tanto, se puede hablar de una sinestesia emocional.

Sin embargo, no se necesita manifestar un grado de sinestesia profundo para realizar este tipo de variaciones a la hora de conocer a una nueva personalidad. Diariamente, el ser humano conoce personas nuevas dada su condición sociable, lo más natural es que evalúe según sus emociones la personalidad de los nuevos sujetos, ya sean estos agradables o no. Usualmente, las primeras impresiones tardan en variar y suelen ser constantes a lo largo del tiempo; una vez que conoces a alguien que tiene rasgos arrogantes/prepotentes es muy difí- cil que aquella persona modifique tus sensaciones con respecto a ella, por más que lo intente.

Si bien es cierto que el estudio de la sinestesia se caracteriza por ser muy actual y no contar con tantos años de antigüedad que lo soporten, es evidente que en el caso de una persona que manifieste los claros síntomas del tipo de sinestesia descrito anteriormente, sus acciones, pensamientos y emociones se verán condicionados con base en ella. En este caso, suponiendo que esta persona sea el líder de una compañía trasnacional y tenga una reunión con sus nuevos asociados, la condición de sinestesia tipo aura va a ejercer un efecto catalizador dentro de los nuevos proyectos que pudieran firmarse. $\mathrm{Si}$, por ejemplo, el líder de esta compañía entra a la sala lleno de expectativas por conocer a los nuevos socios y se encuentra con que uno de ellos tiene un color agresivo a la vista, instantáneamente tomará una actitud defensiva ante él, situación que puede limitar los posibles planes y aspiraciones futuras que ambos tenían anteriormente dentro de sus posibilidades.

Aunque la sinestesia puede conllevar distintas variaciones, no todas están asociadas a la visión de colores únicamente. Otra desviación que podría ser relevante para los efectos organizacionales es aquella que está catalogada como persona-animal. De acuerdo con De Córdoba y Gómez (2014), el sinésteta que manifiesta este tipo de variación suele asociar a las personas de su entorno con animales. Tal es el caso de una bailarina rusa, que conformó parte en su estudio, la cual además de manifestar el estilo de sinestesia grafema-color, tenía muy desarrollada la variación de personaanimal. La bailarina en cuestión, además de asociar los pasos de ballet con colores específicos, identificaba los rostros de las personas conocidas con animales, utilizando frecuentemente para describirlo expresiones muy propias como "Mi madre es una tortuga" o "Mi esposo es un caballo". 
A primera vista no parece ser tan problemática. Sin embargo, debido a los diferentes tipos de personalidades que convergen dentro de las instituciones, el sinésteta se puede encontrar con problemas de asociación del tipo "Mi jefe es un león" o "Mi compañero es una serpiente". En el caso de que esta persona sufra de un miedo inconmensurable a las serpientes, la relación con su compañero se va a ver afectada, pues se mostrará temeroso al momento de establecer una conexión, o creerá que de alguna manera su compañero tiene intenciones ocultas, pues a las serpientes en el imaginario popular occidental se les suele asociar con problemas.

Atendiendo a estas consideraciones, se puede observar que la condición sinestésica es inherente al género humano. En este sentido, las organizaciones, conformadas en su mayoría por personas naturales, no están exentas de contar con individuos como estos dentro de su conformación. Por esta razón, es fundamental y preciso que dentro de las mismas se cuente con personal capacitado (departamento de psicología interno) que pueda brindar ayuda en casos como el mencionado previamente. No solamente para identificar a las personas sinéstetas que puedan encontrarse $\mathrm{y}$, en función a ello, establecer políticas especiales, sino para comprender mejor la manera en la que éstas establecen sus relaciones interpersonales con los demás miembros de la organización.

\section{Mentalidad de un sinésteta y su influjo en la comunicación asertiva: Un nuevo método para aproximar a las personas}

Cuando se habla de comunicación asertiva se comprende que se hace referencia a un elemento imprescindible dentro de la organización. En todo ámbito humano, la confluencia de ideas y pensamientos para la comprensión de los demás seres coe- xistentes ha tomado parte fundamental y protagónica. En este sentido, para Van Der Hofstadt y Gómez (2013), la persona que posee un estilo de comunicación asertiva es aquella capaz de expresar sus ideas, pensamientos y emociones eficazmente, respetando la mentalidad propia de los demás a su alrededor; es a su vez, un facilitador de la comunicación que en todo momento busca la convergencia de ideas, utilizando para ello los canales y conductos adecuados.

Para Van Der Hofstadt (2005), la comunicación es el cemento de la vida social. De esta manera, funciona como el pegamento que une o desune a un determinado sector social, y es precisamente allí donde radica la importancia de la misma. La escucha activa es un ejemplo de comunicación asertiva, mas la interpretación que se le da al mensaje es particular para cada persona y no tiene que ver con la direccionalidad de la misma.

En efecto, esta interpretación, considerada como elemento comunicativo, influye la manera en la que se dicta el mensaje, el canal y la disponibilidad del receptor para recibirlo; de todo ello depende el resultado. Igualmente, es necesario tomar en cuenta los distintos arquetipos comunicativos y de personalidad, ya que esto se va a convertir en un módulo importante que influye insistentemente dentro del proceso de comunicación.

Las personas que manejan un tipo de comunicación asertiva generalmente suelen estar interesadas en la opinión, sentimientos y pensar del otro sujeto con el cual se establece la conexión. Para ello establecen preguntas de toda índole que van dirigidas al ser interno o tienen interés por la condición del interlocutor. Van Der Hofstadt y Gómez (2013) resumen los principales elementos de la comunicación del estilo asertivo en tres grandes ámbitos: 
Tabla 2

Elementos de la comunicación asertiva.

\begin{tabular}{|c|c|}
\hline Elementos de comunicación & Características \\
\hline Conducta no verbal & $\begin{array}{c}\text {-Contacto ocular directo } \\
\text {-Gestos firmes } \\
\text {-Postura erguida } \\
\text {-Manos sueltas } \\
\text {-Expresión distendida } \\
\text {-Relajación corporal }\end{array}$ \\
\hline Conducta verbal & $\begin{array}{c}\text { “Yo pienso que...” } \\
\text { "Siento que...” } \\
\text { ¿Qué te parece...?” } \\
\text { ¿Cómo podemos...?” } \\
\text { "Hagamos esto...” } \\
\text { ¿Por qué no intentamos...?” } \\
\text { ¿Qué opinas?” }\end{array}$ \\
\hline Conducta paraverbal & $\begin{array}{c}\text {-Volumen de voz conversacional } \\
\text {-Habla fluida } \\
\text {-Tiempo de habla adecuado } \\
\text {-Respeta los silencios } \\
\text {-Sabe escuchar } \\
\text {-Tiene una entonación agradable }\end{array}$ \\
\hline
\end{tabular}

Fuente: Van Der Hofstadt y Gómez (2013).

El sentido asertivo de la comunicación viene determinado por la creencia de que todos los seres humanos son iguales y merecen respeto, por tanto, se actúa de manera empática. Sin embargo, al pensar en la mentalidad de una persona sinestésica, se hace evidente que la misma no tiene la misma funcionalidad de una persona que no presenta este tipo de condición. Es necesario entonces comprender que el cerebro de un sinésteta funciona de una manera distinta y, por esta razón, seguramente reaccionará de maneras poco comprensibles para algunas personas.

Resulta interesante conocer el caso planteado por De Córdoba y Riccò (2012) sobre una mujer con sinestesia color-tacto, la cual manifestaba tener problemas dentro de su organización pues el color verde neón del uniforme le causaba una sensación molesta de escozor en la espalda. De esta manera, el efecto de la sinestesia en los seres humanos puede resultar una gran bendición o una terrible maldición desde la óptica que se lo estudie.
Aun así, no todos los casos son una vertiente negativa pues, al mismo tiempo, el sinésteta es capaz de brindar a la comunicación asertiva elementos que podrían beneficiar la sinergia de la misma. Entre las principales oportunidades que ofrece la mente sinestésica a la aplicación de una buena comunicación organizacional se encuentran:

- El aprendizaje que generará dentro de la institución: la comprensión final de que "No todos somos iguales" favorecerá el intercambio de datos e información entre los departamentos que a la misma pertenecen. "Existen personas que ven el mundo exterior de otra manera, y debo aceptarlas al mismo tiempo que debo comprenderlas para el funcionamiento integral de la organización". Desde este punto de vista, la comunicación se expandirá, abriéndose un poco más a tomar los procesos institucionales desde otro punto de vista que anteriormente no manejaban. 
Para López y Gázquez (2016), la asertividad puede aprenderse y desarrollarse, y es precisamente esto lo que la mentalidad del sinésteta le aporta al proceso comunicativo: versatilidad, flexibilidad y la capacidad de conformar un sistema distinto.

- Al tener en el equipo personas que presenten este tipo de capacidades especiales, se desarrollarán nuevas técnicas para lograr el cumplimiento de objetivos internos; un sinésteta de tipo aura-color puede, por ejemplo, identificar fácilmente los distintos tipos de personalidades que hay dentro de una organización y actuar en función a ello.

- Existirá la necesidad de adaptar al sinésteta durante el proceso de comunicación para crear un modelo propio, por tanto, en la formación de este proceso organizacional se fomentarán las relaciones interpersonales que conducen a la unificación de elementos pertenecientes a la institución, tanto humanos como materiales, que tal vez podrían permanecer aislados.

- Los procesos como, por ejemplo, la planificación estratégica, la creación de nuevas estrategias y tácticas inherentes a la organización necesitarán ser reestablecidos en el caso de que sea un sinésteta la persona encargada de dirigir a la organización, y, por lo tanto, se creará una nueva visión global que deberá ser coordinada nos solamente por los gerentes sino por cada uno de los empleados, proveedores y clientes pertenecientes a la cadena.

- Los sujetos que manifiestan sinestesia usualmente son más soñadores, así como creativos, lo cual representa una ventaja a la hora de desarrollar procesos de renovación de imagen o cambios organizacionales.
De esta manera, la relación o las oportunidades que le presenta la sinestesia a las organizaciones humanas no son más que oportunidades de mejora que se deberían aprovechar. Aunque las personas sinéstetas puedan parecer a primera vista diferentes y perturbadoras, estando fusionadas con un clima organizacional estable y una comunicación asertiva, podrían ayudar a la organización a conseguir resultados inigualables, tanto en la calidad del servicio al cliente como en la optimización de las relaciones humanas de las instituciones modernas.

Por otra parte, sería conveniente mencionar la relación entre el liderazgo y la sinestesia. Si lo que se busca es lograr una comunicación asertiva, es importante el entrenamiento de nuevos líderes que posean capacidades extra sensoriales que le faciliten el trabajo de dirigir una organización. En palabras de Argos y Ezquerra (2014), un líder comunicativo es una persona con capacidades especiales que conlleva a las demás personas participes de un grupo a superar sus obstáculos, mientras atrae el poder hacia sí mismo. Es evidente que un sujeto con la habilidad de clasificar los tipos de personalidades por colores, o archivar documentos específicos en su memoria gracias a las sensaciones táctiles que le producen, sería un líder de gran utilidad para los efectos requeridos dentro de un ambiente laboral.

Igualmente, cabe considerar, que, en cualquier actividad humana, una persona competentemente profesional es aquella que, aparte de llevar a cabo las tareas de su determinada profesión, es capaz también de manejar tareas simples como, por ejemplo, una buena comunicación con sus colegas. Mientras que los conocimientos referentes a la profesionalidad se pueden adquirir en la universidad o en lugares afines, la capacidad de ser receptivo y de mantener buenas relaciones interpersonales es algo que se cultiva con el tiempo. 
Por ello, cabe evaluar cada uno de los aspectos psicológicos que puedan incidir en el proceso de socialización pues son estos elementos los que permitirán que un determinado sujeto actúe de una forma o de otra con respecto a los estímulos que pueda estar recibiendo.

De acuerdo con López (2008), las habilidades sociales son las capacidades propias que nos permiten realizar un mejor manejo $\mathrm{y}$ vivencia de las relaciones que componen el entorno. Cuando el individuo es pequeño, sus relaciones se limitan a la familia, pero a medida que el sujeto va creciendo, se amplía gradualmente su ámbito relacional. En este sentido, es preciso que el individuo esté consciente de cuáles son sus características psicosociales para, una vez conocidas, proceder a la potenciación de las mismas si es que éstas son positivas, o a la erradicación, en el caso de que sean prácticas negativas que deban ser sustituidas por otras que generen más beneficios.

Sin embargo, como se ha demostrado anteriormente, el sujeto sinestésico no tiene opción, simplemente, esa es su manera de ver las cosas, ya sea que le produzca más situaciones negativas que beneficios, o, al contrario. Por esta razón, este tipo de personalidades suelen ser más susceptibles a los estímulos externos y pueden llegar a ser acusados de sentimentales en muchas ocasiones. Es necesario entonces que el sinésteta conozca su condición y mantenga una comunicación asertiva con las demás personas de su entorno para que, de esta forma, pueda lograr ser entendido de una manera correcta, sin complicaciones o distorsiones neuro-emocionales.

De la misma manera, es necesario destacar que este tipo de personalidades no solamente deben aprender a manejar una comunicación fluida, sino también a controlar elementos que, en muchas ocasiones, pertenecen al subconsciente. Para Larruskain (2017), el ser humano está conforma- do por un $95 \%$ de inconsciente y un $5 \%$ de personalidad consciente, lo cual indica que el hombre dice mucho menos de lo que piensa. En este caso, el sinésteta no solamente debe aprender a controlar su manera de sentir, percibir y actuar, sino que también deberá controlar sus reacciones inconscientes ante determinados estímulos que se le presenten.

Sobre la base de las ideas expuestas, el presente estudio ha buscado satisfacer diversas interrogantes a través de diversos postulados teóricos. En muchas ocasiones, las habilidades comunicativas son consideradas como un "don" que poseen algunas personas y otras no. Sin embargo, a través del contenido estudiado, se observa claramente que es a través del autoconocimiento profundo, la investigación y la persistencia que el hombre puede alcanzar a dominar ciertas destrezas que tal vez no creyó nunca poder llevar a cabo.

\section{Metodología}

El presente artículo fue trabajado bajo una metodología cualitativa descriptiva de diseño documental, pues a través de distintas posturas teóricas se evaluó el comportamiento de los sinéstetas organizacionales y su relación con el manejo de una comunicación efectiva y asertiva dentro de las instituciones en donde estos laboran. Fue a través de una compleja investigación teórica que se pudo concretar un entramado que sirvió como base para realizar un constructo en donde pudieron reposar y encontrar respuestas acertadas las inquietudes planteadas por los autores.

Para Yuni y Urbano (2005), las metodologías cualitativas poseen criterios y procedimientos lógicos que les permiten alcanzar la validez y confiabilidad de sus teorías. Se caracterizan por tener un carácter flexible, multifacético y estar dirigidas tanto hacia adelante como hacia atrás; poseen proce- 
dimientos y modos de razonamiento que le son propios, los cuales establecen sus propios modelos de validación de conocimientos obtenidos.

Asimismo, se describió y enumeró la serie de características que presentan los sujetos sinéstetas, relacionando éstas con la comunicación asertiva dentro de las instituciones. De acuerdo con Sabino (2006), las investigaciones descriptivas tienen como propósito conocer el comportamiento de grupos indistintos de fenómenos para determinar, de esta manera, una descripción sólida acerca de sus características. Igualmente, Gallardo y Camacho (2008) expresan que las investigaciones de corte descriptivo persiguen el fin de conocer las características de una determinada población; las investigaciones descriptivas suelen realizar un sondeo o realizar un diagnóstico acerca de una situación determinada que está acaeciendo a una muestra de sujetos determinados en la línea del tiempo.

Con respecto a las investigaciones documentales, también llamada bibliográfica o de archivo, Ballén, Pulido y Zúñiga (2007) las describen como aquellas circunscritas a una técnica cualitativa que, a través de la compilación de documentos escritos, tradiciones orales, o cualquier medio investigativo, le permite al investigador conocer más acerca de un tema determinado. De esta manera, mientras más fuentes teóricas se consulten, más fidedigno será el trabajo, pues contará con el respaldo de autores que previamente han manifestado mantener un conocimiento profundo acerca del tema objeto de estudio.

De esta manera, el tipo de investigación cualitativa, descriptiva y documental resulta de gran utilidad, tanto para los investigadores como para los futuros lectores, pues no solamente se comparten los puntos de vista de distintos autores (incluyendo a los de la investigación en cuestión), sino que también se manifiesta como un constructo claro de convergencia de ideas, en donde confluyen personalidades, pensamientos y reflexiones pertenecientes a diversas personas de distintas líneas de tiempo.

\section{El sinésteta organizacional, una visión de futura promesa en la comunicación asertiva de alto impacto}

De acuerdo con Bauman (2010), las organizaciones de hoy en día han sufrido cambios vertiginosos de estados, pasando de ser estructuras sólidas a ser organizaciones líquidas, en donde todo (incluyendo los procedimientos más especiales) fluye. Desde los edificios que la componen, hasta el capital intelectual de sus empleados, la única constante es el cambio. En este sentido, la premisa de estas empresas puede considerarse tomando como insignia la famosa frase de Heráclito: "Es imposible bañarse dos veces en el mismo río, ya que ni el agua ni tú serán los mismos".

En efecto, las compañías actuales se están encargando de implementar nuevos modelos y roles organizacionales que vienen a ser banderas en este nuevo sistema líquido. Tomando en cuenta la nueva generación multitasking, o multitarea, se comprende que los entornos de comunicación vislumbran nuevos horizontes; de esta manera, el sinésteta se perfila como un comunicador con funcionalidades múltiples, debido a que cuenta con las capacidades y habilidades necesarias para encajar dentro de este perfil.

La persona que presenta una condición sinestésica es por naturaleza propensa a las emocionalidades y a la comprensión del otro como ser humano, puesto que constantemente se encuentra asediada por diferentes estímulos que provocan sensaciones distintas y únicas. Este ser, quien es naturalmente distinto, desde su infancia ha estado sometido al señalamiento; por tanto, 
reconoce la pluralidad, entiende que cada ser humano es especial, con pensamientos y sentimientos precisos e inefables, cualidad que se considera base en el proceso comunicacional.

Sobre el asunto, González (2011) señala que la comunicación asertiva debe ser una acción realizada por el individuo para su propio placer y disfrute. Se trata de inmiscuirse en situaciones en las cuales el tiempo vuela y las acciones se convierten en elementos simples que se suceden rápidamente. Al momento de comunicarse, el sujeto se encuentra completamente absorto en la visión del receptor que lo está escuchando, se inmiscuye con sus orígenes, entremezclándose con el mismo mensaje que está emitiendo.

Vinculado al concepto de la sinestesia, es comprensible que en algunos ámbitos que involucren el diseño de piezas específicas, tal vez se pueda presentar alguna problemática; sin embargo, en el ámbito de la creatividad, de la versatilidad y de la innovación, la constante del sinésteta va a tender siempre a ser progresista. Aunque, desde el punto de vista psicológico, no se puede predecir la conducta humana en determinadas situaciones, sí se puede tener una aproximación determinada en las reacciones que se tendrán con base en los rasgos de personalidad que manifiesta cada individuo.

Para De Córdoba y Gómez (2014), las personas usualmente se cierran cuando conocen a alguien que manifiesta características sinestésicas, y suelen confundir su condición con alguna enfermedad o desorden mental. Sin embargo, como se ha mencionado anteriormente, estos se encuentran psicológicamente dentro de los límites normales de conducta humana; por el contrario, algunos sujetos manifiestan una creatividad sin límites, desarrollo avanzado de la memoria eidética y un coeficiente intelectual elevado.
Cabe destacar que una organización que cuente con este tipo de individuos dentro de su talento humano estará ganando beneficios indiscutibles que vienen inmersos en las cualidades de este tipo de sujetos. En el ámbito de la comunicación, la memoria eidética (carácter desarrollado por los sinestésicos) es fundamental, puesto que al tener un nivel pronunciado de ME (memoria eidética), se puede registrar detalladamente eventos del pasado o evocar emociones que le permitan al interlocutor en cuestión manifestar sus pensamientos con claridad y consecuencia, lo cual conllevaría indiscutiblemente a mejorar sus relaciones interpersonales.

En mismo orden de ideas, la comunicación asertiva consiste en expresar opiniones y emitir valoraciones empáticas hacia el receptor, determinándose ésta como la vía más adecuada para la interrelación o el "puente personal" que une a dos individuos. Si este puente se encuentra roto o en malas condiciones, el resultado del proceso comunicativo no será el mismo. De esta manera, para hacer posible el desarrollo de una comunicación asertiva es necesario mantener un control y manejo de emociones adecuado, lo cual pone de manifiesto que la versatilidad del sinestésico le permite mantener un equilibrio conveniente, adaptándose a las situaciones y tomando a la comunicación asertiva como lo que es: una fundamental vía que permite hacer que dos mundos se encuentren.

\section{Sinestésicos egregios}

A lo largo de las décadas, la condición sinestésica ha generado su influjo en diversas categorías artísticas como la música, pintura, y arquitectura. Es abundante el número de personajes históricos que han decidido aprovechar su condición para desarrollar su obra personal. En este sentido, se habla de individuos de carácter, personalidades que universalmente se han aceptado como íconos sociales poderosos dentro de sus ámbitos de accionar. 
Ahora bien, aunque estos pensadores/artistas han sido considerados, en su mayoría, como figuras sentimentales, y en algunos casos, extravagantes, no cabe duda de que su desenvolvimiento como figuras destacadas supera al de otros protagonistas que no presentan la cualidad sinestésica. A lo largo de diversas épocas, muchas figuras sinestésicas han sido consideradas como "elementos adelantados a su tiempo", sin embargo, es necesario comprender que un hombre visionario no está adelantado a la estación en la que vive, por el contrario, es el tiempo quien se ha quedado atrasado.
Así, seconsidera pertinentehacer referencia a estas personas, quienes indistintamente han ejercido su influjo benéfico en la historia del mundo, manejando siempre una constante moderna y profesando el don de cambio. Si se observa claramente el detalle que a continuación se enlistará, a simple vista son notables en los elementos características como, por ejemplo, el liderazgo, la creatividad, la originalidad y capacidad para la resolución de problemas, rasgos fuertemente ligados al desarrollo de una comunicación asertiva de alto impacto.

Tabla 3

\begin{tabular}{|c|c|c|c|c|}
\hline Figura & Campo & Arquetipo & Cita & Rasgos \\
\hline $\begin{array}{l}\text { Wassily } \\
\text { Kandinsky } \\
(1866-1944)\end{array}$ & Pintura & $\begin{array}{l}\text { Sonido-color } \\
\text { Forma-emoción }\end{array}$ & $\begin{array}{l}\text { "El tono del } \\
\text { contrabajo representa } \\
\text { para mi toda la fuerza } \\
\text { de las horas del } \\
\text { crepúsculo..." } \\
\text { "El circulo es la } \\
\text { forma más pacífica } \\
\text { y representa el alma } \\
\text { humana..." }\end{array}$ & $\begin{array}{l}\text {-Sutileza } \\
\text {-Evolución espiritual } \\
\text {-Originalidad } \\
\text {-Creatividad } \\
\text {-Inspiración }\end{array}$ \\
\hline $\begin{array}{l}\text { Arthur } \\
\text { Rimbaud } \\
(1854-1891)\end{array}$ & Literatura & Letra-color & $\begin{array}{l}\text { "Las letras manan } \\
\text { a mi alrededor como } \\
\text { colores de piedras } \\
\text { preciosas..." }\end{array}$ & $\begin{array}{l}\text {-Simbolismo } \\
\text {-Modernismo literario } \\
\text {-Apertura de creación a } \\
\text { la "Metáfora sinestésica" }\end{array}$ \\
\hline $\begin{array}{l}\text { Franz Liszt } \\
(1811-1886)\end{array}$ & Música & Sonido-color & $\begin{array}{l}\text { (Dirigiendo a la } \\
\text { orquesta de Weimar } \\
\text { en 1842) "Por favor } \\
\text { caballeros, hagan } \\
\text { ese tono un poco más } \\
\text { azul..." }\end{array}$ & $\begin{array}{l}\text {-Creatividad } \\
\text {-Liderazgo } \\
\text {-Calidad de auténtico } \\
\text {-Sentimentalismo } \\
\text {-Modernismo }\end{array}$ \\
\hline $\begin{array}{l}\text { Marilyn } \\
\text { Monroe } \\
(1926-1962)\end{array}$ & Actuación/modelaje & Sonido-tacto & $\begin{array}{l}\text { "Soy una piedra que } \\
\text { recibe vibraciones con } \\
\text { cada sonido" }\end{array}$ & $\begin{array}{l}\text {-Versatilidad } \\
\text {-Adaptabilidad } \\
\text {-Hipersensibilidad } \\
\text {-Liderazgo } \\
\text {-Generosidad } \\
\text {-Empatía }\end{array}$ \\
\hline $\begin{array}{l}\text { Jimmy } \\
\text { Hendrix } \\
(1942-1970)\end{array}$ & Música & Sonido-color & $\begin{array}{l}\text { Creador del acorde } \\
\text { C7\#9. Al respecto } \\
\text { indicó que su } \\
\text { nombre es "neblina } \\
\text { púrpura", ya que eso } \\
\text { visualizaba cuando lo } \\
\text { interpretaba. }\end{array}$ & $\begin{array}{l}\text {-Originalidad } \\
\text {-Creatividad } \\
\text {-Memoria eidética } \\
\text {-Liderazgo } \\
\text {-Innovación }\end{array}$ \\
\hline
\end{tabular}

Fuente: elaboración propia (2017). 


\section{Conclusiones}

La mayoría de las personas se preguntan por qué se presentan ciertas situaciones o por qué suceden las cosas de la manera en que se desenvuelven. A pesar de los estudios de psicología acerca de la mente humana, la complejidad del cerebro y las emociones es tal que es prácticamente imposible determinar patrones de conducta estrictamente certeros. De esta manera, al ser humano sobre el ser humano solamente le ha tocado inferir, deducir y estimar ciertas aproximaciones que en muchas ocasiones vienen determinadas por patrones sociológicos o genéticos.

Sobre la cuestión de si los gerentes actuales deben conocer acerca de la presencia de la sinestesia en la organización, no cabe duda alguna al respecto. De acuerdo con De Córdoba (2015), el 6,10 \% de la población hispanoamericana podría experimentar o ha experimentado sensaciones sinestésicas en algún momento de su vida, ya sea esta constante, debido a alguna situación traumática, o de carácter genético. Se habla de una generación completa que mira el mundo bajo este punto de vista, entre ellos puede haber creativos, directores, empleados, jefes, subordinados y altos gerentes empresariales.

La sinestesia organizacional viene a consolidarse como un instrumento específicamente ubicado en la mente de los trabajadores de una empresa, quienes, gracias a sus habilidades especiales, son capaces de producir resultados beneficiosos para la institución en la cual laboran. Es a través de la sinestesia que se puede abrir un abanico de oportunidades en las cuales no se maneje una visión del mundo bilateral; la condición sinestésica le brinda a la organización dinamismo, multiplicidad, creatividad y energía.

Fields y Kelly (2001) expresan en el filme de culto Donnie Darko que los sucesos en la vida no pueden dividirse en dos categorías, nada en este mundo es tan simple como para caber dentro de dos emociones o cinco sentidos fundamentales; existen otros elementos que hay que tomar en cuenta, como el espectro desconocido de las impresiones humanas, la mezcla de sensaciones y la diferenciación en la capacidad de actuar.

De esta manera, el sinésteta organizacional se vislumbra como un personaje visionario, que en muchas ocasiones puede llegar a comprender procesos comunicativos profundos y complejos, los cuales podrían tomarle años a personas que no tienen este tipo de condición. Si se vislumbra a las organizaciones como sistemas, se comprende que dentro de ellas existe una cantidad inagotable de elementos vivos que se encuentran interrelacionados entre sí; que algunos de estos elementos posean características especiales, como la sinestesia, solamente puede significar la potenciación del sistema.

El ser humano, bajo la perspectiva de ser social, se encuentra en constante dependencia de los demás elementos del sistema (otros seres humanos), trabajando en una inmutable interacción con ellos, por esta razón sus potencialidades deberían estar orientadas a la búsqueda de un justo igualitario. Es impresionante lo fácil que resulta adaptarse al cambio organizacional cuando hay alguno de los miembros que se encuentra en constante movimiento, y precisamente es ésta la constante sinestésica.

Sobre la validez de las ideas anteriormente expuestas, se comprende que el papel de la sinestesia en las organizaciones actuales y su influencia en los procesos comunicativos se encuentra íntimamente ligado a los procesos mentales, y desde esta óptica, el ser sinestético debe considerar ésta condición como una oportunidad que se le brinda para mejorar su entorno laboral y mejorarse también a sí mismo, pues por alguna razón (aún desconocida por la ciencia y por 
los datos estadísticos) se le han brindado herramientas especiales para optimizar los procesos organizacionales.

\section{Referencias}

Argos, J. y Ezquerra, P. (2014). Liderazgo y Educación. Santander, España: Publican Ediciones, Universidad de Cantabria.

Bauman, Z. (2010). Mundo consumo: ética del individuo en la aldea global. Barcelona, España: Ediciones Paidós.

Ballén, M., Pulido, R. y Zúñiga, F. (2007). Abordaje hermenéutico de la investigación cualitativa: teorías, procesos, técnicas. Bogotá: Universidad Cooperativa de Colombia, Educc.

Bermúdez, J., Pérez-García, A., Ruiz, J., Sanjuán, P. y Rueda, B. (2013). Psicología de la Personalidad. Madrid, España: Editorial UNED (Universidad Nacional de Educación a Distancia).

Contreras, M., Botella, J., Cabestrero, R. y Gil-Gómez, B. (2013). Lecturas de Psicología experimental. Madrid, España: Editorial UNED (Universidad Nacional de Educación a Distancia).

De Córdoba, M. (2015). Porcentaje de la población con posible sinestesia color/ voz/textura en paises de habla hispana. Artículo publicado en el $V$ Congreso Internacional de Sinestesia, Ciencia y Arte 2015, At Alcalá la Real (Jaén), España.

De Córdoba, M. y Gómez, E. (2014). Flexibilidad Mental. Primera edición. Granada, España: Ediciones Fundación Internacional Arte Citt⿳亠㐅冋.

De Córdoba, M. y Riccò, D. (2012). Sinestesia: Los fundamentos teóricos, artísticos y científicos. Segunda edición ampliada. Granada, España: Ediciones Fundación Internacional ArteCittà.
Dunn, J. y Plomin, R. (1984). The study of temperament: changes, continuities, and challenges. Primera edición publicada en Psycology Press. Estados Unidos de América (EEUU): Informa Company.

Fields, A. (productor) y Kelly, R. (director). (2001). Donnie Darko. [Filme]. Estados Unidos de América: Flower Films.

Gallardo, P. y Camacho, J. (2008). La investigación participativa y su aplicación en el campo social y educativo. Sevilla, España: Editorial Wanceulen, S.L.

González, S. (2011). Habilidades de comunicación hablada: asertividad, persuasión, alto impacto. Nashville, Estados Unidos de América: Editorial Grupo Nelson.

Harrison, J. (2004). El extraño fenómeno de la sinestesia. Biblioteca de Psicología, Psiquiatría y Psicoanálisis. Estados Unidos de América (EE.UU): Fondo de Cultura Económica.

Hathaway, S. y Mckingley, J. (1967). Inventario Multifásico de Personalidad de Minnesota. Adaptación española de Ávila, A. y Jiménez, F. (1999). Universidad de Salamanca, España.

Larruskain, M. (2017). ¿Qué es la bioneuroemoción? [Página Web]. Recuperado de http://mireyalarruskain. com/que-es-la-bioneuroemocion/

López, M. (2008). La integración de las habilidades sociales en la escuela como estrategia para la salud emocional. Psicología sin Fronteras, Revista Electrónica de Intervención Psicosocial y Psicología Comunitaria, 3(1): 16-19.

López, F. y Gázquez, A. (2016). Ciencia administrativa y estrategias de salud. Madrid, España: Editorial ACCI (Asociación Cultural y Científica Iberoamericana). 
Sabino, C. (2006). Los caminos de la ciencia: una introducción al método científico. Buenos Aires, Argentina: Editorial Lumen Humanitas.

Van Der Hofstadt, C. (2005). El libro de las habilidades de comunicación: cómo mejorar la comunicación personal. Segunda edición. Madrid, España: Ediciones Díaz de Santos, S.A.
Van Der Hofstadt, C. y Gómez, J. (2013). Competencias y habilidades profesionales para universitarios. Madrid, España: Ediciones Díaz de Santos, S.A.

Yuni, J. y Urbano, C. (2005). Mapas y herramientas para conocer la escuela: investigación etnográfica. Investigación - acción. Metodologías cualitativas de investigación. Buenos Aires, Argentina: Editorial Brujas. 